\title{
A Novel Tool to Enhance The Lubricant Efficiency On Induction Heat-Assisted Incremental Sheet Forming of Ti-6Al-4V Sheets
}

\section{Weining Li ( $\sim$ WXL713@student.bham.ac.uk)}

University of Birmingham https://orcid.org/0000-0002-8844-564X

Khamis Essa

University of Birmingham

Sheng Li

University of Birmingham

\section{Research Article}

Keywords: hot incremental sheet forming, lubricant, wear, surface roughness, micro-hardness, microstructural analysis, geometric accuracy, thickness profile

Posted Date: January 11th, 2022

DOI: https://doi.org/10.21203/rs.3.rs-1217532/v1

License: (c) (i) This work is licensed under a Creative Commons Attribution 4.0 International License. Read Full License 


\section{Abstract}

For heat-assisted single point incremental sheet forming (SPIF) works of Ti-6Al-4V sheets, the use of lubricant has shown significant effects on surface quality and geometric accuracy at higher temperatures. Molybdenum disulphide $\left(\mathrm{MoS}_{2}\right)$ is a common lubricant widely used in SPIF works, however, it usually indicates ineffective performance at high temperatures. This article has studied different lubricants of $\mathrm{MoS}_{2}$ lubricants and proposed a novel mixture of $\mathrm{MoS}_{2}$ to provide better surface quality and improve geometric accuracy. A forming tool with a ball-roller and water channel was designed to enable the $\mathrm{MoS}_{2}$ mixture to pass through the tool tip, allowing easy application of the lubricant on the localised area and reduce the thermal expansion on the ball-roller. Surface roughness analysis has revealed that the water-cooling $\mathrm{MoS}_{2}$ mixture performed well in reducing friction effects and achieved better geometric accuracy. Forming forces measurements, scanning electron microscope (SEM), energy dispersive X-ray Analysis (EDX) and micro-hardness tests also indicated that a higher strain hardening behaviour was detected for the water-cooling $\mathrm{MoS}_{2}$ mixture.

\section{Highlights}

- First time apply ball-roller tool in heat-assisted incremental sheet forming to direct liquid lubricant to reduce the friction on workpiece surface.

- Three lubricants were tested and analysed in different ways to reveal the mechanical properties including forming force, geometric accuracy, thickness profile and surface roughness.

- The relationship between the mechanical properties and microstructural behaviours including SEM, EDX and micro-hardness have been studied to reveal the performance of the lubricant and the effects on mechanical and microstructural behaviours.

\section{Introduction}

Single-point incremental forming (SPIF) is a flexible sheet forming process which has been investigated over decades to deform sheet metal to produce complicated prototypes. However, the deformation of high strength materials, such as Ti-6Al-4V alloy, remains a challenge. In recent years, the heat-assisted SPIF process has been thoroughly researched to produce a heat source that is able to soften and deform the materials to the designated shape. For instance, Honarpisheh, Abdolhoseini [1] applied an electrical current system to the SPIF to deform the Ti-6Al-4V sheet at a temperature range of 400 to $500^{\circ} \mathrm{C}$. The sheet was successfully deformed to the designated shape with various wall angles. However, the passthrough of a high current flux on the workpiece produced electric sparks at the contact area of the forming tool and the workpiece surface, which significantly affected the surface quality. As the current flux passed through the whole workpiece, the geometric accuracy was also affected. Another study by Göttmann, Bailly [2] applied a laser heating source to the SPIF system, which enabled a localised temperature to be applied on the Ti-6Al-4V sheet, which improved the geometric accuracy. However, the laser heating also raised the risk of cracks occurring in the workpiece and the performance of the surface 
quality was impaired. To improve the surface quality and retain geometric accuracy, recent studies by Ambrogio, Gagliardi [3] introduced an induction heating SPIF system, which enabled localised heating that was generated from the sheet material's centre. The results showed high geometric accuracy of Ti$6 \mathrm{Al}-4 \mathrm{~V}$ deformed sheets and with a reduced risk of cracks. However, the surface quality suffered and had declined at the end of the process. Among the heat-assisted SPIF systems, it can be seen that the surface roughness is a serious challenge that occurred in all hot SPIF processes.

$\mathrm{MoS}_{2}$ is the most common lubricant used in the majority of hot SPIF works. By researching electric heatassisted SPIF of Ti-6Al-4V studies [4, 5], it could be seen that the common $\mathrm{MoS}_{2}$ was insufficient at temperatures above $450^{\circ} \mathrm{C}$, with electric sparks having a significant effect on the removal of the watersolubility of the lubricant. As the tool passed through the lubricant ash, the remaining lubricant adhered to the surface increasing the wear, which affected the surface quality. Another study by Liu, Lu [6] proposed a novel ball-roller for electric heat-assisted SPIF of Ti-6Al-4V sheets, which provided a better surface quality by reducing friction between the tool and the workpiece with common machine grease. The studies of induction heat-assisted SPIF works of Ti-6Al-4V have revealed a slightly better outcome as shown in the study by Ambrogio, Gagliardi [7]. Results revealed that without the effects of electric sparks, the common $\mathrm{MoS}_{2}$ paste is more functional than when used with electric heat-assisted SPIF with the assistance of cryogenic cooling. However, the rapid change of temperature on the upper and lower surface of the workpiece still resulted in the ineffectiveness of the lubricant and an unsustainable performance. Another study by Ortiz, Penalva [8] revealed that high-temperature lubricant oil in induction heat-assisted SPIF of Ti-6Al-4V sheets produced more favourable results showed that on surface quality than the common low-temperature lubricants. However, the sustainability was still insufficient at the end of the process, with a large amount of adhered wear observed.

In summary, it was revealed that the performance of the surface quality is mainly attributed to the effectiveness and sustainability of lubricants during the process. The majority of common lubricants are ineffective at the higher temperature (above $400^{\circ} \mathrm{C}$ ) deforming process. The dissipation of lubricant in the high-temperature SPIF is a common phenomenon that results in significant adhesion wear. In this analysis, a Nickel alloy ball-roller tool has been designed and integrated into a high-frequency induction heat-assisted SPIF system. By increasing and maintaining a localised temperature of $700^{\circ} \mathrm{C}$, the performance of different lubricants has been studied, and a novel method of lubricant application was proposed to improve the surface quality and remain geometric accuracy.

\section{Materials And Methods \\ 2.1. Materials}

All workpieces in this analysis were standard hot-rolling Ti-6Al-4V alloy sheets with a size of $150 \mathrm{~mm} x$ $150 \mathrm{~mm}$ and a thickness of $0.8 \mathrm{~mm}$. The chemical composition of the Ti-6Al-4V alloy used is shown in Table 1. 
Table 1

Chemical composition of Ti-6Al-4V

\begin{tabular}{|llllllll|}
\hline Ti & Al & V & C & $\mathbf{O}$ & $\mathbf{N}$ & H & Fe \\
\hline Balanced & 5.3 & 3.8 & 0.1 & 0.2 & 0.05 & 0.01 & 0.3 \\
\hline
\end{tabular}

The lubricants used in this analysis can be classified into three lubricants. Lubricant 1, provided by CRC $\mathrm{Ltd}$, is a standard graphite grease that consists of graphite particles and $\mathrm{MoS}_{2}$ paste. According to the supplier information, the lubricant can be serviced between $-30^{\circ} \mathrm{C}$ and $650^{\circ} \mathrm{C}$. lubricant 2 is a mixture of lubricant 1 and machine lubricant oil provided by Ambersil Ltd, which has a protective agent based on rust inhibitors and surfactants enabling it to reduce friction and wear on the workpiece surface. According to the supplier information, the lubricant oil can service up to $300^{\circ} \mathrm{C}$. Lubricant 3 has used lubricant 2 as the main component on the workpiece surface with an external liquid lubricant from the water cooling channel. The liquid lubricant is a mixture of coolant with $\mathrm{MoS}_{2}$ powder. The coolant is provided by AZURE Ltd, which contains anti-corrosion additives to reduce friction and rust. The $\mathrm{MoS}_{2}$ powder is $98.5 \%$ pure with an average of $1.5 \mu \mathrm{m}$ particle size provided by OKS Spezialschmierstoffe GmbH Ltd. To mix $\mathrm{MoS}_{2}$ powder with the coolant, DISPERMAT shear dissolver was used. According to the previous study by Hussain, Gao [9] on the investigation on lubricant effects on SPIF, high weight (20\%) of $\mathrm{MoS}_{2}$ powder has been used to increase the dispersion. However, it can be seen that the mixture lubricant has not provided high surface quality. The other study by Azevedo, Farias [10] has commented that high condensation can be observed in the dispersion of lubricant powder in water which affects the performance of mixture lubricant. Diabb, Rodríguez [11] has proposed that the small size powder has better solubility in other liquid agents. The shear dissolver can provide a high shear force to dissolve the $\mathrm{MoS}_{2}$ powder into the coolant by laminate orientation without the phenomenon of condensation. The details of each lubricant are illustrated in Table 2.

Table 2

Details of lubricants

\begin{tabular}{|llll|}
\hline Lubricant & Content & Mix method & State \\
\hline 1 & Graphite grease & Non & Paste \\
\hline 2 & Dispersion of lubricant 1 (20\%) in machine oil & $\begin{array}{l}600 \mathrm{rpm} \text { of } \\
30 \mathrm{mins}\end{array}$ & Paste \\
\hline 3 & $\begin{array}{l}\text { lubricant 2 with external lubricant from water channel } \\
\text { (2\% MoS } 2 \text { powder in water coolant) }\end{array}$ & $\begin{array}{l}600 \mathrm{rpm} \text { of } \\
60 \mathrm{mins}\end{array}$ & Paste/Liquid \\
\hline
\end{tabular}

\subsection{Tool and SPIF system design}

To deform high strength metal sheets like Ti-6Al-4V, a high forming force is required for the process. Wear and friction tracks are a common phenomenon usually present on the formed workpiece and forming tool $[5,12-15]$. A previous study by Iseki and Naganawa [16] first introduced the ball-roller tool tip to reduce the friction force between a workpiece and the tool tip in the SPIF process. Another study by Liu, Lu [6] 
improved the design with a water cooling channel to achieve better surface quality in electric heatassisted SPIF of Ti-6Al-4V. In this analysis, a $10 \mathrm{~mm}$ IN 625 nickel ball was attached to the stainless-steel forming tool to enable a rotational motion. According to the supplier's information, the maximum operating temperature is $980^{\circ} \mathrm{C}$, which is sufficient for this study. To reduce the thermo-expansion on the ball-roller tool tip, the tool shank was made with a hollow inner structure that allowed the water to flow in and out with a separation board. The details of the tool design are illustrated in Figure 1. During the experiment, a water container with a tube was connected to the water-in valve and another tube connected the water-out valve to a water tank. The water tube was $5 \mathrm{~mm}$ diameter and connected to a pump with power of $300 \mathrm{rpm}$ throughout the whole process.

The induction heating system for the SPIF design is displayed in Figure 2. The induction heating machine has a $900 \mathrm{kHz}$ alternating current (AC) inductor with a maximum power of $6.6 \mathrm{KW}$. An electromagnetic field is generated between the workpiece and the heating coil as shown in Figure 2(a). A rapid eddy current is created from the centre of the workpiece to the outer surface, enabling recrystallisation from the inside of the material without affecting the surface features. To provide accurate localised heating, the heating coil diameter is $10 \mathrm{~mm}$, the same as that of the ball-roller tool tip as shown in Figure 2(b). The induction heater can provide a rapid and constant temperature to the workpiece with an error of $2 \%$ for at least 20 hours. A flexible support fixture has been designed to connect the heating head and tool to allow a synchronised movement in XYZ directions. A $50 \mathrm{kN}$ low profile diaphragm load cell and an infrared thermo-couple have been fixed on the tool to measure the reaction force from the tool and monitor the temperature change. The measurement range of the thermocouple is $400^{\circ} \mathrm{C}$ to $1200^{\circ} \mathrm{C}$ with an error of $2 \%$.

\subsection{Experimental parameters}

The final shape is a truncated cone that has a $100 \mathrm{~mm}$ major diameter, $30 \mathrm{~mm}$ height, and $45^{\circ}$ wall angle as shown in Figure 3.

The tool path was generated by MATLAB, and a G-code was obtained from the MATLAB coordinates output file to be used as a toolpath to control the computer numerical control (CNC) machine. The detailed parameters and working temperatures are listed in Table 3.

Table 3

Experimental parameters

\begin{tabular}{|ll|}
\hline Experimental parameters & Target temperature $\left(7^{\circ}{ }^{\circ} \mathrm{C}\right)$ \\
\hline Feed rate $(\mathrm{mm} / \mathrm{min})$ & 1000 \\
\hline Step size & 1.0 \\
\hline Power $(\mathrm{kW})$ & 5.5 \\
\hline Frequency $(\mathrm{kHz})$ & 700 \\
\hline
\end{tabular}




\section{Results And Discussion}

\subsection{Temperature distribution and forming force}

The temperature distribution for experiments with lubricants 1,2 and 3 are illustrated in Figure 4 . It can be seen that the temperature distributions for lubricants 1 and 2 are very close, the temperature rose rapidly for around $30 \mathrm{~s}$ to a relatively steady-state stage and then increased gradually, but marginally, until the end of the process. The temperature at the end of the experiment (final $100 \mathrm{~s}$ ) was around $20^{\circ} \mathrm{C}$ higher than the target temperature $\left(700^{\circ} \mathrm{C}\right)$. As the forming area was getting smaller, according to the SPIF process, the temperature was more concentrated thus resulting in a re-heating behaviour that increased the temperature. For the lubricant 3 experiment, it took around $60 \mathrm{~s}$ to increase the temperature to the steady-state stage and it maintained that level almost constantly until the end of the process. It was evident that the water-cooling system was sufficient to balance the temperature increase throughout the process. It should be noted that the measured temperature distributions were smoothed using SavitzkyGolay smoothing filter [17] to reduce the noise.

The forming force profiles from the experiments with lubricants 1, 2 and 3 are illustrated in Figure 5. Lubricants 1 and 2 have relatively similar profiles, whilst lubricant 3 differs. This is mainly attributed to the effects of water cooling throughout the process. As the sustainable localised coolant support from the forming tool, the hot strain-hardening work on the workpiece surface is reduced which results in a higher forming force, especially at the initiation stage. By comparing the results with the previous study by Honarpisheh, Abdolhoseini [1], on electric heating SPIF, and another by Al-Obaidi, Kräusel [18], on induction heating assisted SPIF of Ti-6Al-4V sheet, it could be found that the forming force at the initiation stage is unstable, as the dynamic recrystallisation (DRX) at this stage is insufficient to form isotropic microstructure to maintain a constant forming force. This is the same reason for the forming force growth in this article. Due to the sustainable support of coolant, the temperature distribution on the surface of the lubricant 3 experiment is maintained better than lubricants 1 and 2 thus resulting in a relatively graduate growth of forming force. Please note that forming profiles are smoothed by Golay smoothing filters to reduce the noise frequency.

\subsection{Surface roughness}

For each formed workpiece (using lubricants 1, 2 and 3), three sections $\left(5 \mathrm{~mm}^{2}\right)$ were removed from the upper, centre and lower regions to determine surface roughness. All measurements were taken using the Alicona Infinite Focus optical 3D surface measurement system with a $50 \mathrm{~nm}$ minimum vertical resolution and $0.03 \mu \mathrm{m}$ minimum measurable roughness and $2 \%$ error.

The cut samples and optical microscope measured data for lubricants 1, 2 and 3experiments are illustrated in Figure 6, Figure 7 and Figure 8.

It can be observed from Figure 6(a) that lubricant 1 produced the worst performance as wear tracks and cracks appeared on the workpiece surface. From the upper to lower region (Figure $6[\mathrm{~b}-\mathrm{d}]$ ), the lubricant 
dissipated according to the process. However, since the heating temperature was higher than that recommended for the lubricant, the rapid dissipation resulted in a layer of contamination that adhered to the forming tool and workpiece surface, which increased the friction force that caused adhesive and abrasive wear. Similar results were observed in a study by Najafabady and Ghaei [5], on high-temperature SPIF of Ti-6Al-4V sheets, providing additional evidence that insufficient support from the lubricant is a common challenge in the high-temperature SPIF process. As the process progressed from the upper to lower region, the increase in temperature and dissipation of lubricant lead to severe wear tracks that formed surface cracks incrementally, resulting in unfavourable surface quality.

For lubricant 2, the result is displayed in Figure 7(a), it can be seen that the surface quality is much better than for lubricant 1. There are no observable surface cracks on the upper region as shown in Figure 7(b), and the centre and lower regions, shown in Figure $7(\mathbf{c}-\mathbf{d})$, also reveal better surface quality. The lubricant oil from lubricant 2 indicated a strong reason to retain the presence of lubricant 1 in high-temperature SPIF work. Although lubricant 2 was not functional throughout the whole process, the lubricant still exhibited enhanced performance over lubricant 1.

The best surface quality was achieved with lubricant 3, as shown in Figure 8(a). It can be observed that the wear tracks increased from the upper region to the centre region, Figure $8(\mathbf{b}-\mathrm{c})$, with slight cracks present on the lower region as seen in Figure 8(d). These results provide evidence that the sustainable coolant lubricant support from the water-cooling system is sufficient to reduce friction on the workpiece. Referring back to Figure 4, it appears that the coolant lubricant also functioned to balance temperature within a steady range, enabling lubricant 3 to remain effective throughout the whole high-temperature SPIF process. The surface quality of lubricant 3 is observable better than lubricant 1 and 2 , and the results are comparable with the study by Ao, Gao [19], on electric heat-assisted SPIF of Ti-6Al-4V sheets which has indicated significant current-carrying wear, and another study by Ambrogio, Filice [4], on induction heat-assisted SPIF of Ti-6Al-4V sheets where severe adhesive wear remained.

The 3D surface topography roughness measurements of lubricants 1, 2 and 3 (upper, centre and lower) samples are presented in Figure 9 to Figure 11. The readings of average area surface roughness ( $\left.\{\backslash \text { text }\{S\}\}_{-}\{\mid t e x t\{a\}\}\right)$ are shown in Figure 12. The detail roughness values of root-mean-square height $\left(\{\backslash \operatorname{text}\{S\}\}_{-}\{\backslash \operatorname{text}\{q\}\}\right)$, maximum peak height $\left\{(\backslash \operatorname{text}\{S\}\}_{-}\{\backslash\right.$ text $\left.\{p\}\}\right)$, maximum valley depth $\left\{(\backslash \operatorname{text}\{S\}\}_{-}\{\backslash \operatorname{text}\{\mathrm{v}\}\}\right)$, maximum height $\left\{(\backslash \operatorname{text}\{S\}\}_{-}\{\backslash \operatorname{text}\{z\}\}\right)$ of each lubricant of lubricant are listed in Table 4.

In Figure $9(\mathbf{b}-\mathbf{c})$, it can be seen that lubricant 1 produced a high density of surface cracks on the centre and lower regions and these cracks expand a high difference between the workpiece outer surface layer and substrate. lubricant 2, Figure 10(b-c), reduced the effects significantly, and no observable surface cracks appeared when using lubricant 3 , Figure $11(b-c)$.

Figure 12shows that the growth of surface roughness was the same for all three lubricants. The measurements of $S_{a}$ increased incrementally through the process. The increase in $S_{a}$ with lubricant 2 is 
less pronounced than for lubricant 1, and lubricant 3 results in the lowest growth trend. These results agree with the observations were seen in Figure 6 to Figure 8.

By investigating the measured amplitude parameters of each sample in Table 4, it can be observed that the $S_{q}$ is following the same trend as $S_{a}$. This provides evidence that friction is increased as the lubricant dissipates. It should be noticed that the $S_{z}$ values (difference between $S_{q}$ and $S_{v}$ ) upper regions of all three lubricants are in similar values, indicating the effective performance of the lubricants at upper regions. The $S_{z}$ values for lubricant 1 centre and lower regions are incredible high, providing clear evidence that surface cracks destroyed the workpiece surface and left a valley between the outer layer and substrate. lubricant 2 generated slightly less damage, with significantly improved results with lubricant 3. Please note that all presented data were filtered by the Gaussian filter for inclined planar surfaces to reduce the noise.

Table 4

Measured amplitude parameters of each lubricant sample

\begin{tabular}{|c|c|c|c|c|}
\hline & $\begin{array}{l}\{\operatorname{text}\{S\}\} \_\{t \operatorname{text}\{q\}\} \\
(\mu \mathrm{m})\end{array}$ & $\begin{array}{l}\{t \operatorname{text}\{S\}\} \_\{t \operatorname{text}\{p\}\} \\
(\mu \mathrm{m})\end{array}$ & $\left\{\begin{array}{l}\{\operatorname{text}\{S\}\} \_\{t \operatorname{text}\{v\}\} \\
(\mu \mathrm{m})\end{array}\right.$ & $\begin{array}{l}\{1 \operatorname{text}\{S\}\} \_\{t \operatorname{text}\{z\}\} \\
(\mu \mathrm{m})\end{array}$ \\
\hline $\begin{array}{l}\text { lubricant } 1 \\
\text { upper region }\end{array}$ & 1.012 & 5.221 & 3.827 & 9.048 \\
\hline $\begin{array}{l}\text { lubricant } 1 \\
\text { centre region }\end{array}$ & 2.116 & 6.098 & 5.751 & 11.849 \\
\hline $\begin{array}{l}\text { lubricant } 1 \\
\text { lower region }\end{array}$ & 2.261 & 6.985 & 6.913 & 13.898 \\
\hline $\begin{array}{l}\text { lubricant } 2 \\
\text { upper region }\end{array}$ & 0.806 & 5.005 & 1.509 & 6.514 \\
\hline $\begin{array}{l}\text { lubricant } 2 \\
\text { centre region }\end{array}$ & 1.381 & 6.135 & 5.593 & 11.728 \\
\hline $\begin{array}{l}\text { lubricant } 2 \\
\text { lower region }\end{array}$ & 1.913 & 6.774 & 5.622 & 12.436 \\
\hline $\begin{array}{l}\text { lubricant } 3 \\
\text { upper region }\end{array}$ & 0.504 & 2.155 & 1.334 & 3.444 \\
\hline $\begin{array}{l}\text { lubricant } 3 \\
\text { centre region }\end{array}$ & 1.051 & 2.744 & 3.636 & 6.380 \\
\hline $\begin{array}{l}\text { lubricant } 3 \\
\text { lower region }\end{array}$ & 2.247 & 4.185 & 4.913 & 9.231 \\
\hline
\end{tabular}

\subsection{Geometric profile}

Geometric accuracy is a significant factor that reveals the overall performance and quality characteristics of products made by the SPIF process. The FARO Edge-scan 8-axis laser 3D scanning arm has been used in this study to measure the 3D geometric accuracy of the deformed parts. The resolution of this system 
is $40 \mu \mathrm{m}$, with an error of $\pm 0.2 \mu \mathrm{m}$. Geomagic was then used to process the cloud of points and obtain a highly accurate measurement of the final profile and thickness distribution.

The geometric profile of lubricants 1, 2 and 3 are shown in Figure 13. The experimentally measured profiles were obtained using FARO 3D scanning on the clamped workpiece to reduce the spring-back effects from unclamping and cooling. As illustrated in Figure 13, there was no significant difference between the three lubricants. By dividing the profiles into three stages, it can be seen that all three lubricants were practically identical at Stage 1 (upper region). lubricant 3 then started to diverge slightly at Stage 2 (centre region), before all three lubricants became diverse from each other at Stage 3. The reasoning can be explained by the temperature and forming force profiles in Figure 4 and Figure 5 . The temperature support for the upper regions of lubricant 1 and 2 experiments was insufficient to dissipate the lubricant. As the process progressed to the centre and lower regions, the dissipation of lubricant was more pronounced, with lubricant 3 revealing a superior geometric profile due to its relatively stable temperature distribution, which enhanced stable forming force measurements and greater control of the growth of geometric accuracy.

It was observed that the successful application of rapid localised heating enhanced the deformation process. Hence, it can be concluded that induction heat-assisted SPIF can deform Ti-6Al-4V sheets with high geometric accuracy by increasing the DRX in the material microstructure. This is a typical phenomenon that occurs in high-temperature SPIF as the thermomechanical behaviour may induce high residual stress and stress relaxation in the material, which can result in spring-back and pillow effects. Similar observations were also reported in a previous study by Ortiz, Penalva [20], on the geometric accuracy of the high-temperature SPIF process.

\subsection{Thickness profile}

For each lubricant, the thickness profiles, measured from the sheet edge to its centre at $600^{\circ} \mathrm{C}$ and $700^{\circ} \mathrm{C}$, respectively, were determined, as illustrates in Figure 14. The sheet thickness was obtained using the FARO 3D scanner for two paths, with one path on the upper surface of the deformed workpiece and the other one on the lower surface. The $X, Y$ and $Z$ coordinates were collected accordingly, and the data obtained using Equation 1, the theoretical thickness profile can be obtained from the sine law as shown in Equation 2. Cao, Lu [21] studied the incremental sheet forming (ISF) process and reported that the sine law is efficient to predict the thickness distribution of deformed parts.

The sheet thickness can be calculated using Equation 1:

$\backslash \operatorname{text}\{t\}=\backslash \operatorname{sqrt}\left\{\left\{\backslash \operatorname{left}\left(\{\backslash \operatorname{text}\{x\}\}_{-}\{1\}-\{\mid \operatorname{text}\{x\}\}_{-}\{2\} \backslash \operatorname{right}\right)\right\}^{\wedge}\{2\}+\left\{\backslash \operatorname{left}\left(\{\backslash \operatorname{text}\{\mathrm{y}\}\}_{-}\{1\}-\backslash \operatorname{text}\{\mathrm{y}\}\right\}_{-}\{2\} \backslash \operatorname{right}\right)\right\}^{\wedge}\{2\}^{+}$ $\left.\left\{\backslash \operatorname{left}\left(\{\backslash \operatorname{text}\{z\}\}_{-}\{1\}-\{\backslash \operatorname{text}\{z\}\}_{-}\{2\} \backslash \text { right }\right)\right\}^{\wedge}\{2\}\right\}(1)$

Where $t$ is denoted as the sheet thickness, $\{\mid \operatorname{text}\{x\}\}_{-}\{1\},\{\mid \operatorname{text}\{y\}\}_{-}\{1\},\{\backslash \operatorname{text}\{z\}\}_{-}\{1\}$ are the coordinates of nodes on the top surface path, $\{\backslash \operatorname{text}\{x\}\}_{-}\{2\},\{\mid \operatorname{text}\{y\}\}_{-}\{2\},\{\mid \text { text }\{z\}\}_{-}\{2\}$ are the coordinates of nodes on the lower surface path. 
The theoretical thickness distribution can be obtained by applying cosine law as in Equation 2:

$\{\mid \operatorname{text}\{t\}\}_{-}\{\mid \operatorname{text}\{f\}\}=\{\backslash \operatorname{text}\{t\}\}_{-}\{0\} \backslash \operatorname{text}\{\sin \}\{\backslash$ theta $\}(2)$

Where $\{\mid \text { text }\{t\}\}_{-}\{$text $\{f\}\}$ is the final thickness of the workpiece, $\{\mid \operatorname{text}\{t\}\}_{-}\{0\}$ is the initial thickness of the workpiece, $\{\backslash$ theta $\}$ is the wall angle.

This equation was proposed in a previous study by Hussain and Gao [22], to estimate the thickness distribution in SPIF. Lu, Fang [23] also applied the same principle to predict the theoretical thickness of double-side ISF. Another study by Tolipov, Elghawail [24], on multi-point forming, again verified the equation's efficiency in estimating the thickness distribution in sheet metal forming.

As illustrated in Figure 14, it can be seen that the sheet thinning is proportional to the cone depth. The sine law predicted sheet thinning of $0.565 \mathrm{~mm}$ for a $45^{\circ}$ wall angle. By dividing the profile into 3 stages, it is observed that all three lubricants had diverse growth at Stage 1 before converging into Stage 2 . However, as Stages 2 progress diversity was detected again at the thinnest thickness area, before convergence at Stage 3. Similar to the geometric profile, such phenomenon can be attributed to the temperature and forming force profile, as shown in Figure 4 and Figure 5, respectively, but with opposite results since the lubricant effects are not sensitive at the early stages. At Stage 1, insufficient temperature and an unstable forming force resulted in differing initial profiles for the three lubricants. Once the temperature and forming force reach a steady-state between Stages 1 and 2, good correspondence was achieved by all three lubricants. The lubricant dissipation effects were shown to be most pronounced at the thinnest thickness area in Stage 2. Here the temperature and forming profile were relatively stable, but the unstable friction force from lubricant 1 was the main reason that caused the change in its profile. Once the critical point is passed at Stage 3, all three lubricants tended to converge as the DRX for all experiments is fairly initiated. Studies by Ao, Gao [19] and Vahdani, Mirnia [25] also reported similar findings for the high-temperature SPIF process of Ti-6Al-4V sheets.

\subsection{SEM}

A tabletop Hitachi TM3030 SEM was used to analyse the microstructure of the as-received and deformed samples. The SEM and EDX images of the investigation area were taken at magnifications of $600 \mathrm{x}$ to $2000 x$ with an accelerating voltage of $15 \mathrm{kV}$. The SEM samples were divided into two groups, surface samples and cross-section samples. The surface samples group: The as-received samples and deformation samples (upper, centre and lower) of each lubricant were cleaned with $70 \%$ alcohol and then ultrasonically cleaned with $100 \mathrm{~W}$ and $40 \mathrm{kHz}$ for 20 mins to remove any contamination from the samples. During the SEM investigation, the area with major surface cracks and contamination were the focus of EDX zone mapping. The cross-section samples group: the cross-section of the as-received sample and deformation samples (upper, centre and lower) for each lubricant were mounted, chemically and mechanically polishing with $0.04 \mu \mathrm{m}$ Colloidal Silica (OP-S) suspension and etching using Kroll's reagent $(2 \mathrm{ml} \mathrm{HF}, 10 \mathrm{ml} \mathrm{HCl}, 88 \mathrm{ml} \mathrm{H} 20)$ to investigate the microstructural evolution throughout the workpiece. 


\subsubsection{SEM investigation on surface samples}

As shown in Figure 15, the black area is the remaining contamination that was impossible to remove from the surface by cleaning. It can be seen that the contamination and surface cracks became more pronounced from the upper to lower region. At the centre region, there was clear growth of micro-cracks that stretch the deformation surface and contaminants were generally located at the boundaries of the micro-cracks. As the growth of micro-cracks increased at the lower region, a large area of the remaining contamination was observed. By cross-referencing with the surface roughness measurements in Figure 9, it could be concluded that the increase of surface roughness is due to the growth of the microstructural cracks and residual contamination. The phenomenon is pronounced for lubricant 1 as apparent cracks and contamination are observed on the centre and lower region scanning area. Lubricant 2 (Figure 16) indicated a better deformation surface as the phenomenon of micro-cracks was reduced by comparing with lubricant 1 (Figure 15). The upper region could be deemed as clean as there was no detectable 'black area' and the micro-cracks at the centre region were reduced significantly. At the lower region, due to dissipation of the lubricant, contamination was detected at different areas rather than one single area. This is clear evidence that lubricant 2 has shown a better surface quality. For lubricant 3 , shown in Figure 17 , no detectable micro-cracks were observed on the upper region and the growth of micro-cracks at the centre and lower region was significantly reduced, which produced the best surface quality among the three lubricants.

\subsubsection{EDX zone mapping}

To investigate the content of the elements of the sample surfaces, EDX analysis was applied to the same scanning area as the SEM investigation. Please note that the red colour is the Molybdenum (Mo) element, the green colour is the Carbon (C) element and the blue colour is the Titanium (Ti) element.

It can be seen from Figure 18 that in the upper region of the lubricant 1 sample there were detectable levels of the elements Mo and C, which are the main components of the lubricant contamination [26]. The growth of the contamination was more apparent at the centre and lower region, where the area with micro-cracks have been covered by these elements. This is clear evidence that the contaminations are caused by the dissipation of lubricants due to the temperature during the process. The loss of lubricating function led to micro-cracks developing on the deformation surface and the contaminants have adhered to the boundaries of the micro-carks thus results in great growth of contamination according to the process. The use of lubricant 2, shown in Figure 19, illustrates a comparably low content of contamination at the upper region indicating there was good functioning of the lubricant at the starting stage. However, in the centre and lower regions, contaminants still adhered due to the dissipation of lubricant. The volume of contamination is significantly reduced for lubricant 3 , as shown in Figure 20 . It can be seen that the detectable content of contamination was very low at the upper region and the growth of contamination was very limited in comparison with lubricants 1 and 2 . A previous study by Careri, Umbrello [27], on the investigation of tool wear in IN718 heat treatments, revealed similar results, and the study concluded that high temperature was the main reason for adhesive wear between the 
workpiece surface and the tool, and the force from the deformation speed enhanced the adhesive wear, resulting in abrasive wear. Other studies [28, 29], on the deformation and sheet forming of titanium alloys, were in agreement that high deformation force and temperature results in the formation of micro-cracks that encourage contaminants from the lubricant to adhere and accumulate at the boundaries of the micro-cracks. A study by Wang, Zhang [30] on the materials removal process also indicated that water cooling has balanced the thermal expansion of the tool in a toolpath with rapid rotating movement. This is evidence that the water-cooling lubricant from the water channel has sustainable support to reduce the thermal effects on the ball-roller tool tip, and enhance the rotating movement in the hot SPIF process.

\subsubsection{SEM investigation on cross-section samples}

To investigate the microstructural evolution through the thickness of the material the lower region samples of each lubricant of lubricant was compared with the as-received sample. As observed in Figure 21 (a), the as-received sample had a microstructure composed of high content of primary a phase with random equiaxed grain shape and an estimated \{lalpha \} grain size from $5-10 \mu \mathrm{m}$. The detectable intergranular $\beta$ phase grains are distributed at the boundaries of the a phase. At the lower region samples of lubricants 2 and 3, Figure 21(b-d), there was a noticeable growth of finer a grains detected and the grain size was significantly reduced. There was no significant difference between the microstructures of the lower region samples, providing evidence that the DRX initiation at $700^{\circ} \mathrm{C}$ was the same for all three lubricants, with the surface quality being the main reason for the differences in forming force and geometric profile.

By comparing with microstructural evolution between the images in Figure $21(b-d)$, it could be seen that there was no clear a-phase detected, which means that no oxidation occurred as a result of the penetration of the lubricants and heating temperature. The observed DRX behaviour was attributed to the high temperature arising from the SPIF process, which is in agreement with a study by Qu, Tang [31], on microstructure and oxidation behaviours of titanium alloy at low temperatures, and another by Ding and Guo [32], on the Ti-6Al-4V alloy at high temperatures, where the heat-treatment of Ti-6Al-4V alloys above $700^{\circ} \mathrm{C}$ was sufficient for initiation of DRX enhancing the ductility and formability for deformation. The continuous increase of temperature above the phase transition $\left(980^{\circ} \mathrm{C}\right)$ may induce the growth of aphase and $\beta$ phase grains, which would significantly affect the microstructural evolution, however, this investigation was not conducted for this paper. The sustainable water-cooling lubricant support from lubricant 3 was sufficient to produce a constant temperature support throughout the experimental process, which provided higher surface quality, geometric accuracy and a thickness profile at an even microstructural evolution when compare with lubricants 1 and 2 .

\subsection{Micro-hardness}

A Wilson ${ }^{\circledR}$ hardness tester was used in this project to provide highly accurate hardness results of the asreceived and deformed samples. The measurements follow the GB/T 4340.1-2009 HV 0.1 metal hardness testing standard with a testing load of $100 \mathrm{gm}$. The machine reading error is $0.5 \%$. 
The micro-hardness measurements were determined by making indents on the surfaces of each deformation and cross-sectional sample. The orientation of the indents was in a step-down arrangement, covering measurements from the upper sample edge to the lower edge. A total of 9 indents were applied to each sample. To illustrate the most significant effects of the samples, only the lower samples were tested.

In Figure 22, it can be seen that for all three lubricants the micro-hardness profile of the deformation surfaces followed a similar flat trendline. lubricants 1 and 2 had very close results whereas lubricant 3 had higher readings. This is supportive evidence that temperature reduction from the water-cooling system is sufficient to enhance the strain hardening process, thus results in higher reading measurements on the deformation surfaces.

Reviewing the micro-hardness profiles for the cross-section samples in Figure 23, it can be seen that the use of lubricants 1 and 2 resulted in a low-high-low distribution profile, whilst lubricant 3 exhibits a highlow profile. Such behaviour can be attributed to the working mechanism of induction heating. In the system, the magnetic field penetrates the workpiece generating a rapid alternating eddy current at the centre of the material, which is then spreading to the outer regions. Thus, due to the mechanism of induction heating and movement of the tool, the highest thermomechanical strain will occur in the centre region in the lubricant 1 and 2 experiments. However, for the lubricant 3 experiment, the water cooling on the workpiece applied a strong strain hardening on the workpiece surface. Such a phenomenon enhanced the hardness readings of the lubricant 3 workpiece deformation surface, thereby balancing the readings between the substrate and outer surface. Once the substrate region is passed, the readings are reduced and tend to get close to lubricant 1 and 2 experiments.

Overall, it can be noticed that the readings on the deformation surfaces were slightly higher than for the cross-section surfaces. A previous study by Dai, Wang [33], on microstructure and hardness of Ti-6Al-4V sheet surface under heat-treatment work, reported that the average hardness readings on the deformation surfaces are higher than on the substrate region, due to the surface finishing process that induces thermal-strain. Such behaviour may result in limited oxidation that enhances the a-stabilising of Ti-6Al-4V, thus increasing surface hardness. It was observed that the deformation process in this analysis applied a strong strain hardening force on the workpiece, which resulted in higher micro-hardness readings.

A previous study by Najafabady and Ghaei [34], on the investigation of effects on the hardness of Ti-6Al$4 \mathrm{~V}$ alloy by heat incremental forming, reported that strain hardening was pronounced at $600^{\circ} \mathrm{C}$, and was effective in increasing the micro-hardness. Another study by Sabat, Surya Pavan [35], on the texture and microstructure evolution of Ti-6Al-4V alloys, revealed that the strain hardening and grain deformation induced higher micro-hardness readings at $600^{\circ} \mathrm{C}$. However, the temperature was insufficient to generate the full DRX process, resulting in the creation of a deforming microstructure, demonstrated by the presence of a strong deformation texture. Using a higher temperature of $700^{\circ} \mathrm{C}$ accelerated the dislocation mobility and resulted in full DRX, which manifested in grain refinement, as shown in the measurements readings in this analysis. 


\section{Conclusion}

- The lubricant grease (lubricant 1) was not sufficient to support the whole induction heat-assisted SPIF process as it dissipated rapidly halfway through the working process. Significant adhesive and abrasive wear were detected and huge areas of surface cracks appeared on the workpiece.

- The mixture of lubricant grease with lubricant oil (lubricant 2) performed better and the sustainability is much longer than the lubricant 1 . Surface quality was also improved.

- The best performance was achieved by applying the water-cooling system to lubricant 2 (lubricant 3 ). The water-cooling system was sufficient to stabilise the temperature profile and produce a relatively gradual increase profile of forming force. Such behaviour enhances the surface quality.

- The geometric profile and the thickness profile calculations indicated that lubricant 3 had a better profile, close to the ideal in comparison to lubricants 1 and 2 .

- The micro-hardness measurements for deformation and cross-section surfaces of all three lubricants of lubricants indicated that lubricant 3 had an effective function to reduce and control the temperature on the deformation surface.

\section{Declarations}

\section{Funding}

The authors declare that no funds, grants, or other support were received during the preparation of this manuscript.

\section{Conflicts of interest/Competing interests}

The authors declare that they have no known competing financial interests or personal relationships that could have appeared to influence the work reported in this paper.

\section{Availability of data and material}

The data included in this study are available upon request by contact with the corresponding author.

\section{Code availability}

Not applicable.

\section{Ethics approval}

Not applicable.

\section{Consent to participate}

Not applicable. 


\section{Consent for publication}

Not applicable.

\section{Authors' contributions}

Weining Li: Conceptualization, Investigation, Methodology, Validation, Formal analysis, Writing - original draft. Khamis Essa: Writing - review \& editing, Resources, Supervision, Project administration. Sheng Li: Writing - review \& editing, Investigation.

\section{References}

1. Honarpisheh, M., M.J. Abdolhoseini, and S. Amini, Experimental and numerical investigation of the hot incremental forming of Ti-6Al-4V sheet using electrical current. The International Journal of Advanced Manufacturing Technology, 2015. 83(9-12): p. 2027-2037. DOI: 10.1007/s00170-015-7717-7.

2. Göttmann, A., et al., A novel approach for temperature control in ISF supported by laser and resistance heating. The International Journal of Advanced Manufacturing Technology, 2012. 67(9-12): p. 2195-2205. DOI: $10.1007 / s 00170-012-4640-z$.

3. Ambrogio, G., et al., Induction heating and cryogenic cooling in single point incremental forming of Ti6Al-4V: process setup and evolution of microstructure and mechanical properties. The International Journal of Advanced Manufacturing Technology, 2016. 91(1-4): p. 803-812. DOI: 10.1007/s00170-0169794-7.

4. Ambrogio, G., L. Filice, and F. Gagliardi, Formability of lightweight alloys by hot incremental sheet forming. Materials \& Design, 2012. 34: p. 501-508. DOI: 10.1016/j.matdes.2011.08.024.

5. Najafabady, S.A. and A. Ghaei, An experimental study on dimensional accuracy, surface quality, and hardness of Ti-6Al-4 $\mathrm{V}$ titanium alloy sheet in hot incremental forming. The International Journal of Advanced Manufacturing Technology, 2016. 87(9-12): p. 3579-3588. DOI: 10.1007/s00170-016-8712-3.

6. Liu, R., et al., Development of novel tools for electricity-assisted incremental sheet forming of titanium alloy. The International Journal of Advanced Manufacturing Technology, 2016. 85(5): p. 1137-1144. DOI: 10.1007/s00170-015-8011-4.

7. Ambrogio, G., et al., Induction heating and cryogenic cooling in single point incremental forming of Ti$6 \mathrm{Al}-4 \mathrm{~V}$ : process setup and evolution of microstructure and mechanical properties. The International Journal of Advanced Manufacturing Technology, 2017. 91(1): p. 803-812. DOI: 10.1007/s00170-0169794-7.

8. Ortiz, M., et al., Accuracy and Surface Quality Improvements in the Manufacturing of Ti-6Al-4V Parts Using Hot Single Point Incremental Forming. Metals, 2019. 9(6): p. 697. 
9. Hussain, G., et al., Tool and lubrication for negative incremental forming of a commercially pure titanium sheet. Journal of Materials Processing Technology, 2008. 203(1-3): p. 193-201. DOI: 10.1016/j.jmatprotec.2007.10.043.

10. Azevedo, N., et al., Lubrication Aspects during Single Point Incremental Forming for Steel and Aluminum Materials. International Journal of Precision Engineering and Manufacturing, 2015. 16: p. 1-7. DOI: 10.1007/s12541-015-0079-0.

11. Diabb, J., et al., Study of lubrication and wear in single point incremental sheet forming (SPIF) process using vegetable oil nanolubricants. Wear, 2017. 376-377: p. 777-785. DOI: https://doi.org/10.1016/j.wear.2017.01.045.

12. Fan, G., et al., Electric hot incremental forming of Ti-6Al-4V titanium sheet. The International Journal of Advanced Manufacturing Technology, 2009. 49(9-12): p. 941-947. DOI: 10.1007/s00170-009-2472-2.

13. Song, X., et al., Numerical and experimental investigation on the deformation mechanism of micro single point incremental forming process. Journal of Manufacturing Processes, 2018. 36: p. 248-254. DOI: https://doi.org/10.1016/j.jmapro.2018.10.035.

14. Yoganjaneyulu, G., C. Sathiya Narayanan, and R. Narayanasamy, Investigation on the fracture behavior of titanium grade 2 sheets by using the single point incremental forming process. Journal of Manufacturing Processes, 2018. 35: p. 197-204. DOI: https://doi.org/10.1016/j.jmapro.2018.07.024.

15. Bong, H.J., et al., Correlative Study on Plastic Response and Formability of Ti-6Al-4V Sheets under Hot Forming Conditions. Journal of Manufacturing Processes, 2020. 58: p. 775-786. DOI: https://doi.org/10.1016/j.jmapro.2020.08.053.

16. Iseki, H. and T. Naganawa, Vertical wall surface forming of rectangular shell using multistage incremental forming with spherical and cylindrical rollers. Journal of Materials Processing Technology, 2002. 130-131: p. 675-679. DOI: 10.1016/s0924-0136(02)00735-5.

17. Press, W.H. and S.A. Teukolsky, Savitzky-Golay Smoothing Filters. Computers in Physics, 1990. 4(6): p. 669-672. DOI: 10.1063/1.4822961.

18. Al-Obaidi, A., V. Kräusel, and D. Landgrebe, Hot single-point incremental forming assisted by induction heating. Vol. 82. 2015.

19. Ao, D., et al., Formability and deformation mechanism of Ti-6Al-4V sheet under electropulsing assisted incremental forming. International Journal of Solids and Structures, 2020. 202: p. 357-367. DOI: https://doi.org/10.1016/j.ijsolstr.2020.06.028.

20. Ortiz, M., et al., Accuracy and Surface Quality Improvements in the Manufacturing of Ti-6Al-4V Parts Using Hot Single Point Incremental Forming. Metals - Open Access Metallurgy Journal, 2019. 9: p. 697. DOI: $10.3390 /$ met9060697. 
21. Cao, T., et al., An efficient method for thickness prediction in multi-pass incremental sheet forming. International Journal of Advanced Manufacturing Technology, 2015. 77(1-4): p. 469-483. DOI: 10.1007/s00170-014-6489-9.

22. Hussain, G. and L. Gao, A novel method to test the thinning limits of sheet metals in negative incremental forming. International Journal of Machine Tools and Manufacture, 2007. 47(3): p. 419-435. DOI: https://doi.org/10.1016/j.ijmachtools.2006.06.015.

23. Lu, B., et al., Investigation of material deformation mechanism in double side incremental sheet forming. International Journal of Machine Tools and Manufacture, 2015. 93: p. 37-48. DOI: 10.1016/j.jjmachtools.2015.03.007.

24. Tolipov, A., et al., Multipoint forming using mesh-type elastic cushion: modelling and experimentation. The International Journal of Advanced Manufacturing Technology, 2019. 103(5): p. 2079-2090. DOI: 10.1007/s00170-019-03635-z.

25. Vahdani, M., et al., Electric hot incremental sheet forming of Ti-6Al-4V titanium, AA6061 aluminum, and DC01 steel sheets. The International Journal of Advanced Manufacturing Technology, 2019. 103(1): p. 1199-1209. DOI: 10.1007/s00170-019-03624-2.

26. Wang, H.-d., Graphite Solid Lubrication Materials, in Encyclopedia of Tribology, Q.J. Wang and Y.-W. Chung, Editors. 2013, Springer US: Boston, MA. p. 1550-1555.

27. Careri, F., et al., The effect of the heat treatments on the tool wear of hybrid Additive Manufacturing of IN718. Wear, 2021. 470-471: p. 203617. DOI: https://doi.org/10.1016/j.wear.2021.203617.

28. Gatea, S., et al., Investigation of the effect of forming parameters in incremental sheet forming using a micromechanics based damage model. International Journal of Material Forming, 2018. 12(4): p. 553574. DOI: 10.1007/s12289-018-1434-3.

29. Bai, M., et al., In-situ Ti-6Al-4V/TiC composites synthesized by reactive spark plasma sintering: processing, microstructure, and dry sliding wear behaviour. Wear, 2019. 432-433: p. 202944. DOI: https://doi.org/10.1016/j.wear.2019.202944.

30. Wang, S., et al., Surface generation and materials removal mechanism in ultra-precision grinding of biconical optics based on slow tool servo with diamond grinding wheels. Journal of Manufacturing Processes, 2021. 72: p. 1-14. DOI: https://doi.org/10.1016/j.jmapro.2021.10.010.

31. Qu, S.J., et al., Microstructural evolution and high-temperature oxidation mechanisms of a titanium aluminide based alloy. Acta Materialia, 2018. 148: p. 300-310. DOI: 10.1016/j.actamat.2018.02.013.

32. Ding, R. and Z.X. Guo, Microstructural evolution of a Ti-6Al-4V alloy during $\beta$-phase processing: experimental and simulative investigations. Materials Science and Engineering: A, 2004. 365(1): p. 172179. DOI: https://doi.org/10.1016/j.msea.2003.09.024. 
33. Dai, J., et al., Characterization and correlation of microstructure and hardness of Ti-6Al-4V sheet surface-treated by pulsed laser. Journal of Alloys and Compounds, 2020. 826: p. 154243. DOI: 10.1016/j.jallcom.2020.154243.

34. Najafabady, S.A. and A. Ghaei, An experimental study on dimensional accuracy, surface quality, and hardness of Ti-6Al-4 $V$ titanium alloy sheet in hot incremental forming. The International Journal of Advanced Manufacturing Technology, 2016. 87(9): p. 3579-3588. DOI: 10.1007/s00170-016-8712-3.

35. Sabat, R.K., et al., Mechanism of texture and microstructure evolution during warm rolling of Ti-6Al4V alloy. Philosophical Magazine, 2018. 98(28): p. 2562-2581. DOI: 10.1080/14786435.2018.1493237.

\section{Figures}

\section{Figure 1}

Tool design: (a) isotropic view of tool design, (a) cross-section view of tool design.

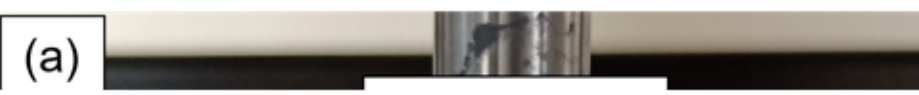

(b) 㖕

\section{Figure 2}

Induction heat-assisted SPIF system: (a) working view of the tool-workpiece-heating coil; (b) fixture of load cell and infrared thermo-couple. 
(a)

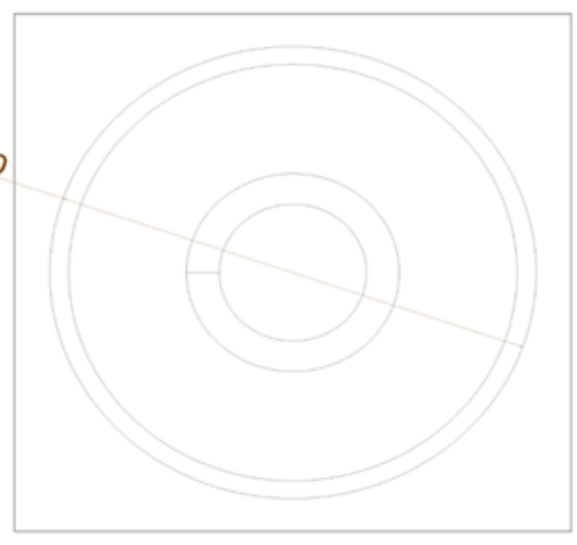

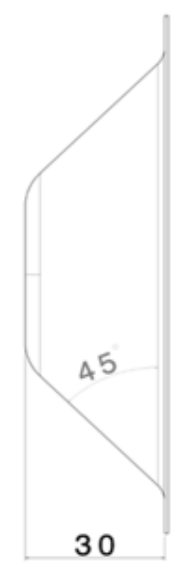

(b)

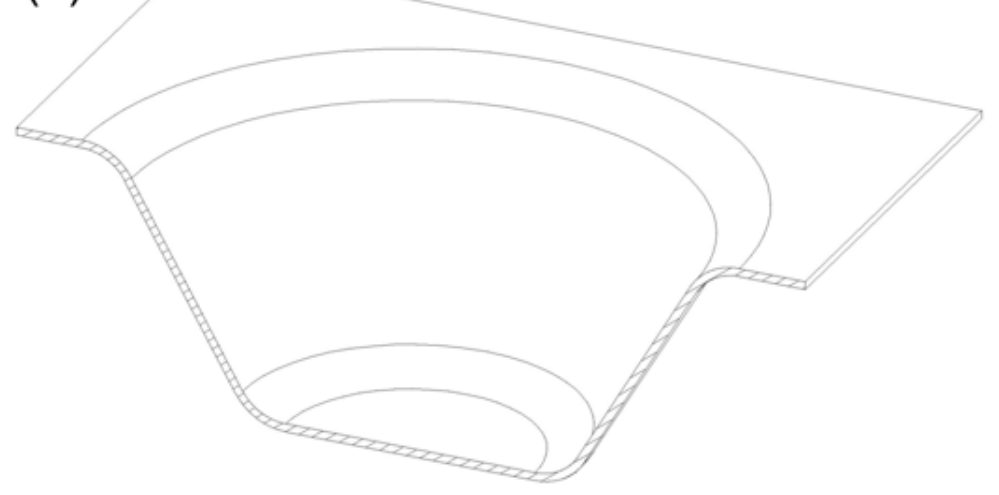

\section{Figure 3}

The design of formed shape: (a) dimensions of the formed shape; (b) isotropic view of the formed shape.

\section{Figure 4}

Measured temperature history for SPIF at $600^{\circ} \mathrm{C}$ and $700^{\circ} \mathrm{C}$. 


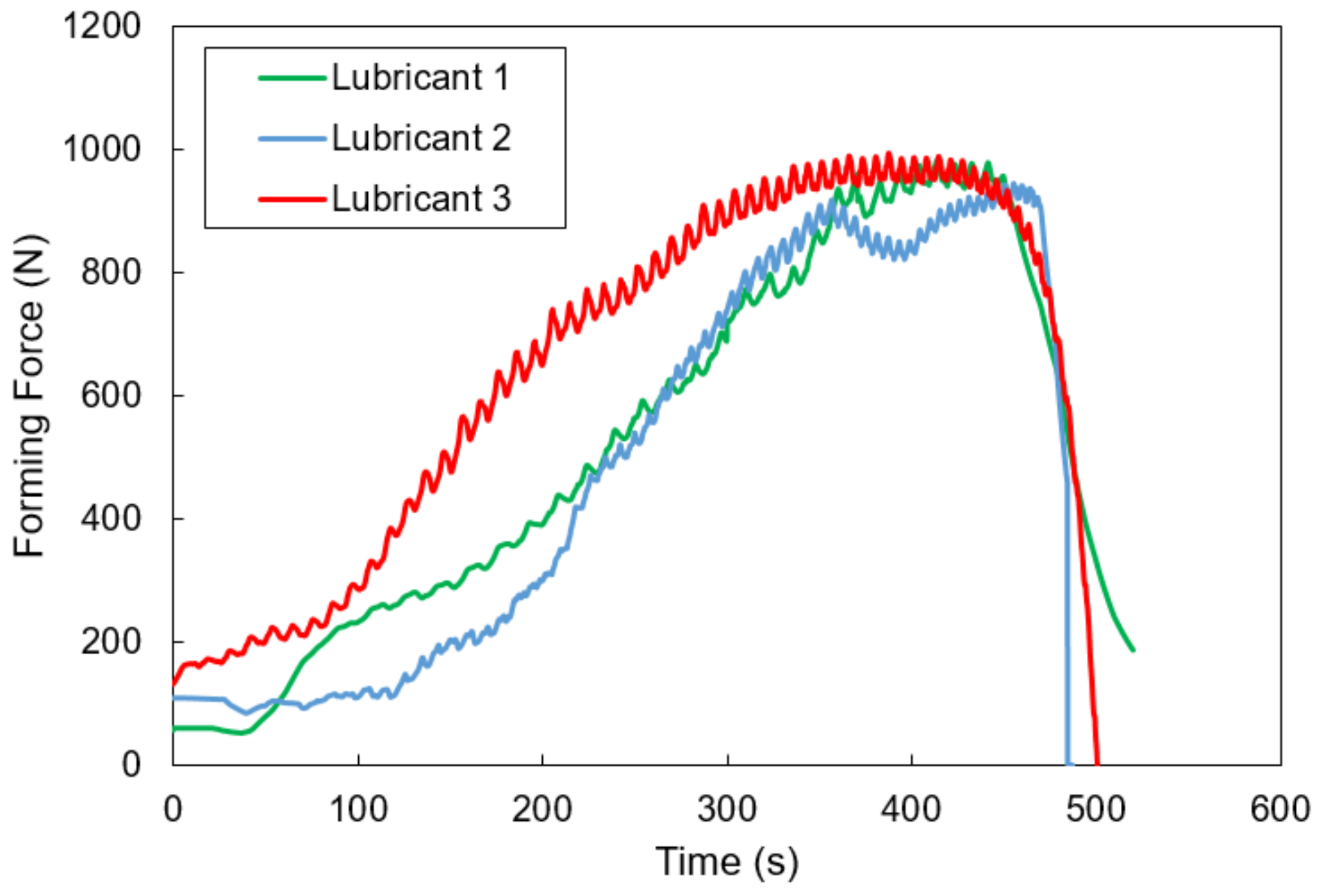

Figure 5

Forming force profiles for lubricant 1,2 and 3 experiments. 


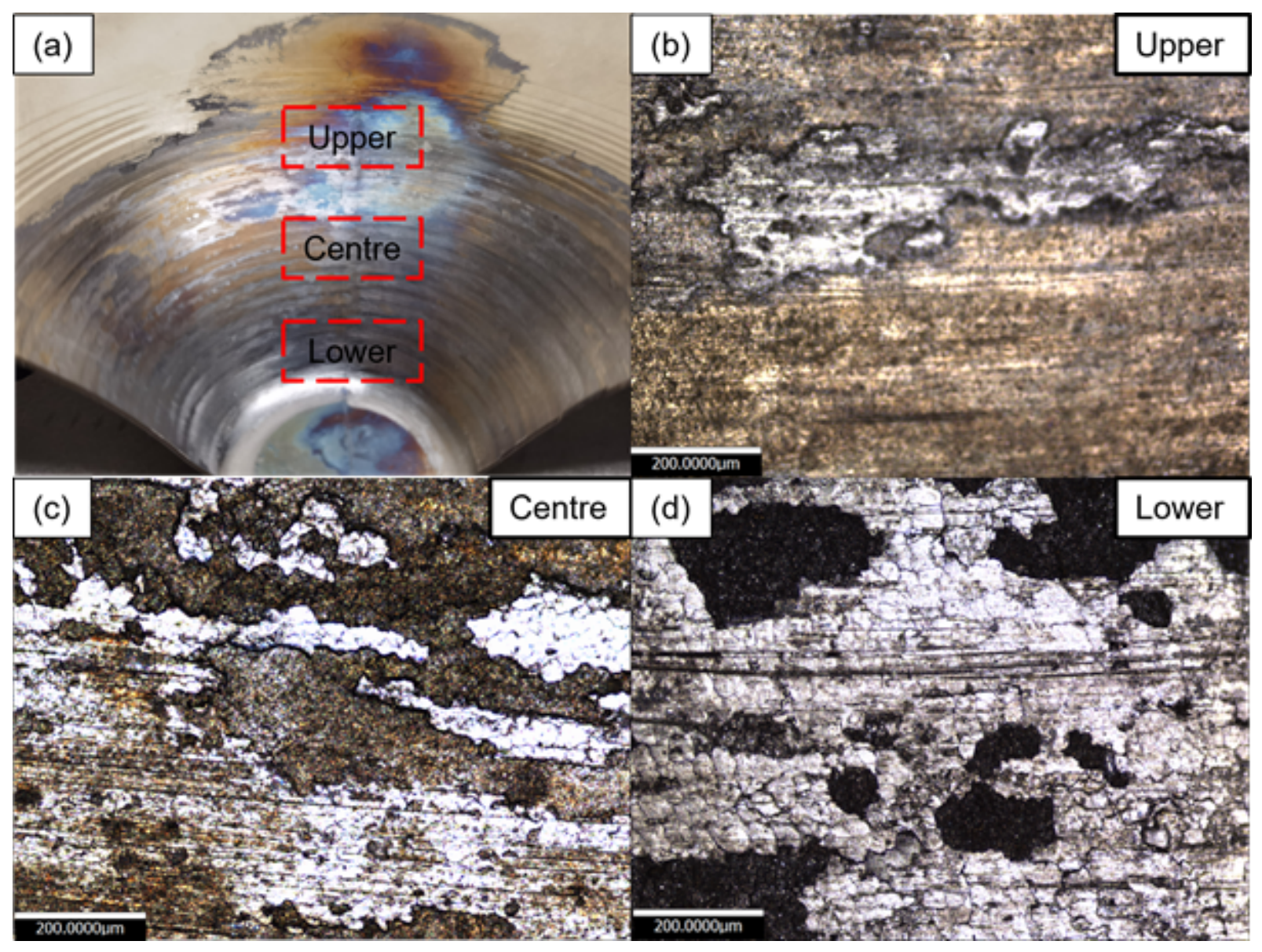

Figure 6

OM measurements for lubricant 1: (a) locations of sample collection; (b) upper region sample; (c) centre region sample; (d) lower region sample. 


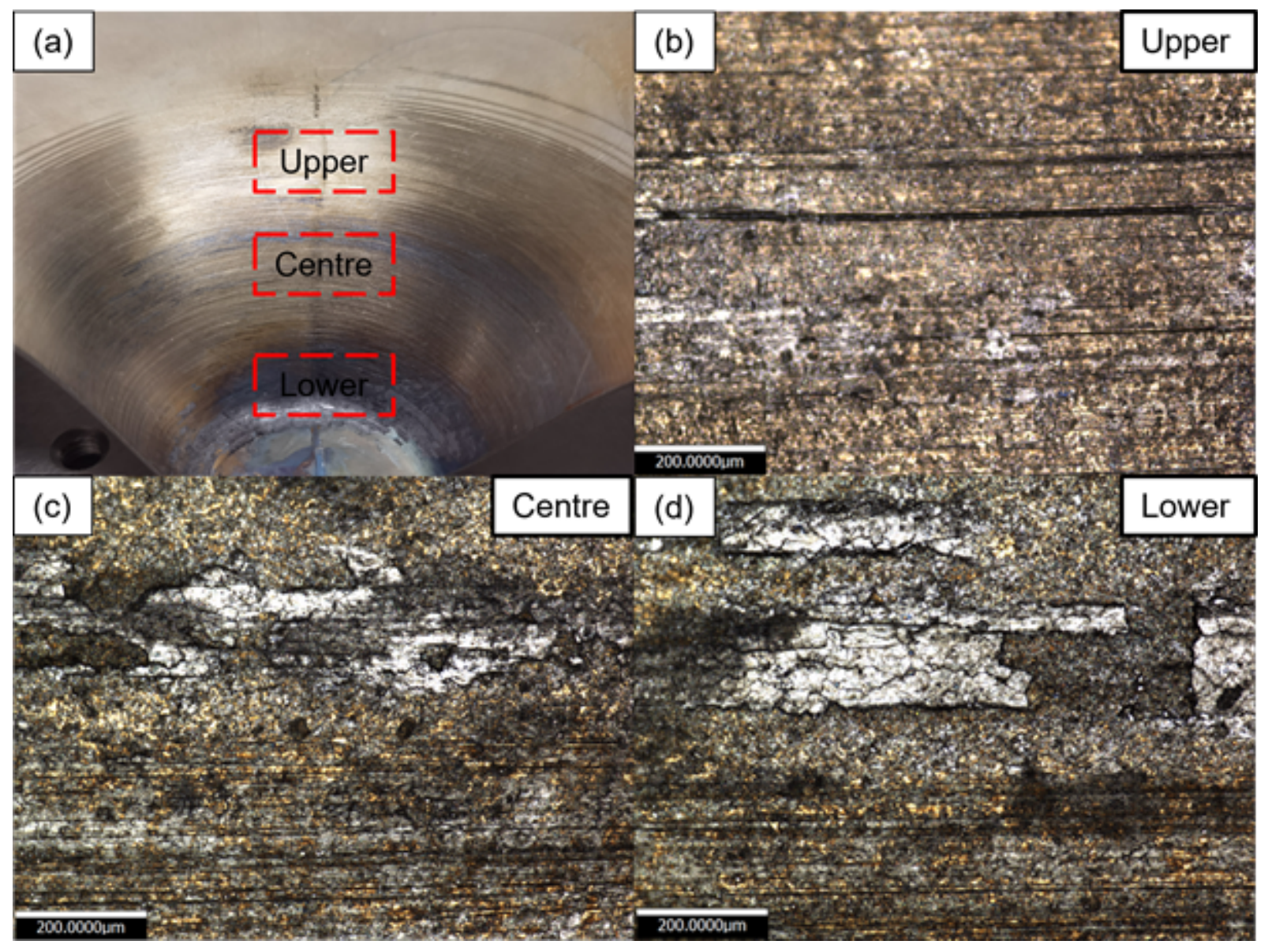

\section{Figure 7}

OM measurements for lubricant 2: (a) locations of sample collection; (b) upper region sample; (c) centre region sample; (d) lower region sample.

\section{Figure 8}

OM measurements for lubricant 3: (a) locations of sample collection; (b) upper region sample; (c) centre region sample; (d) lower region sample. 


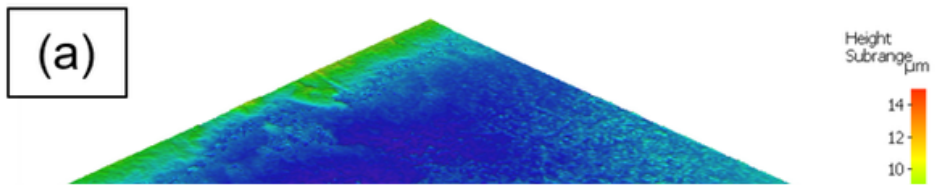

\section{Figure 9}

3D surface topography surface roughness measurements for lubricant 1: (a) upper region; (b) centre region; (c) lower region.

\section{Figure 10}

3D surface topography surface roughness measurements for lubricant 2: (a) upper region; (b) centre region; (c) lower region. 


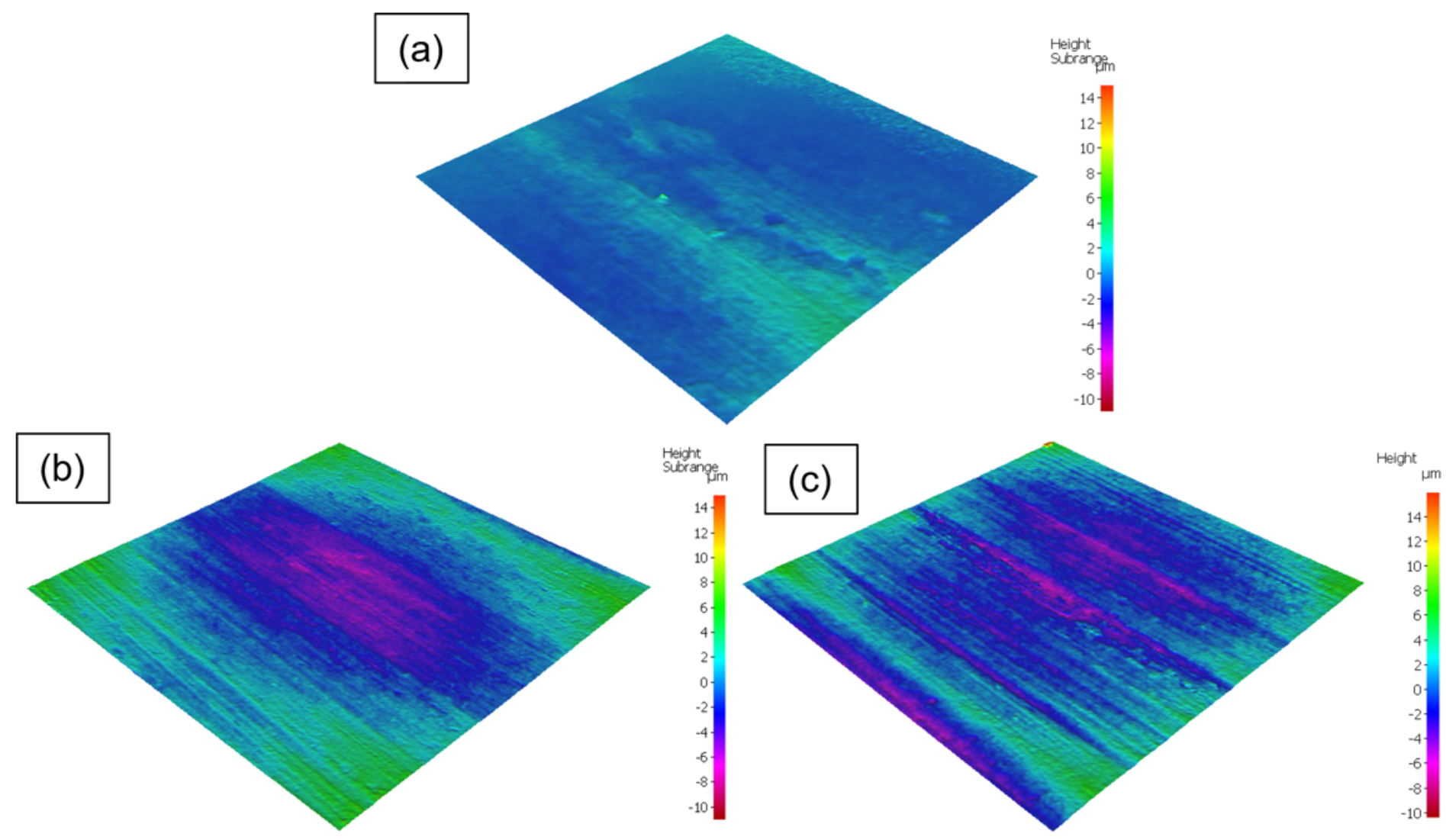

Figure 11

3D surface topography surface roughness measurements for lubricant 3: (a) upper region; (b) centre region; (c) lower region. 


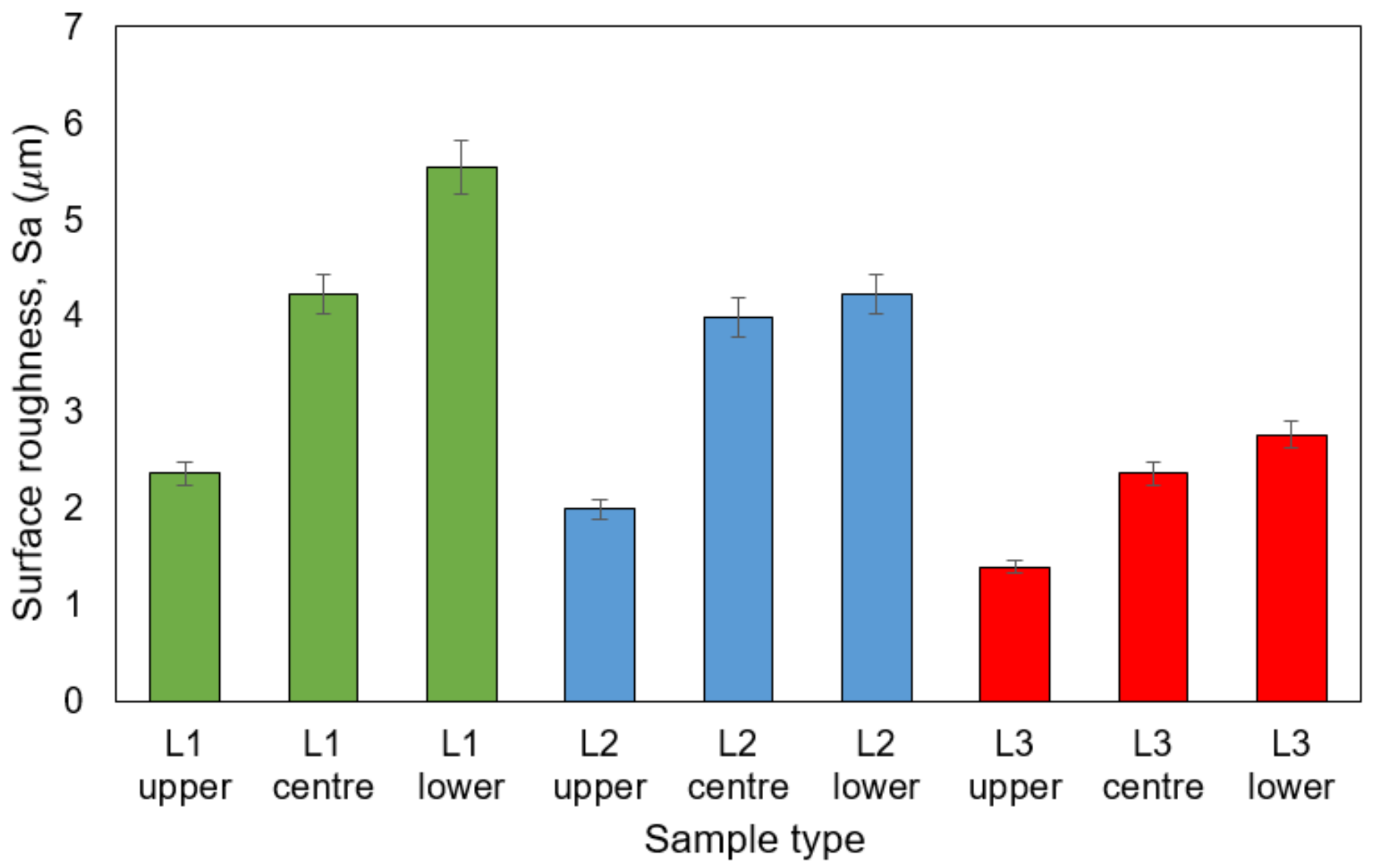

Figure 12

Average surface roughness measurements (Sa) for lubricants 1, 2 and 3 (upper, centre, lower). 


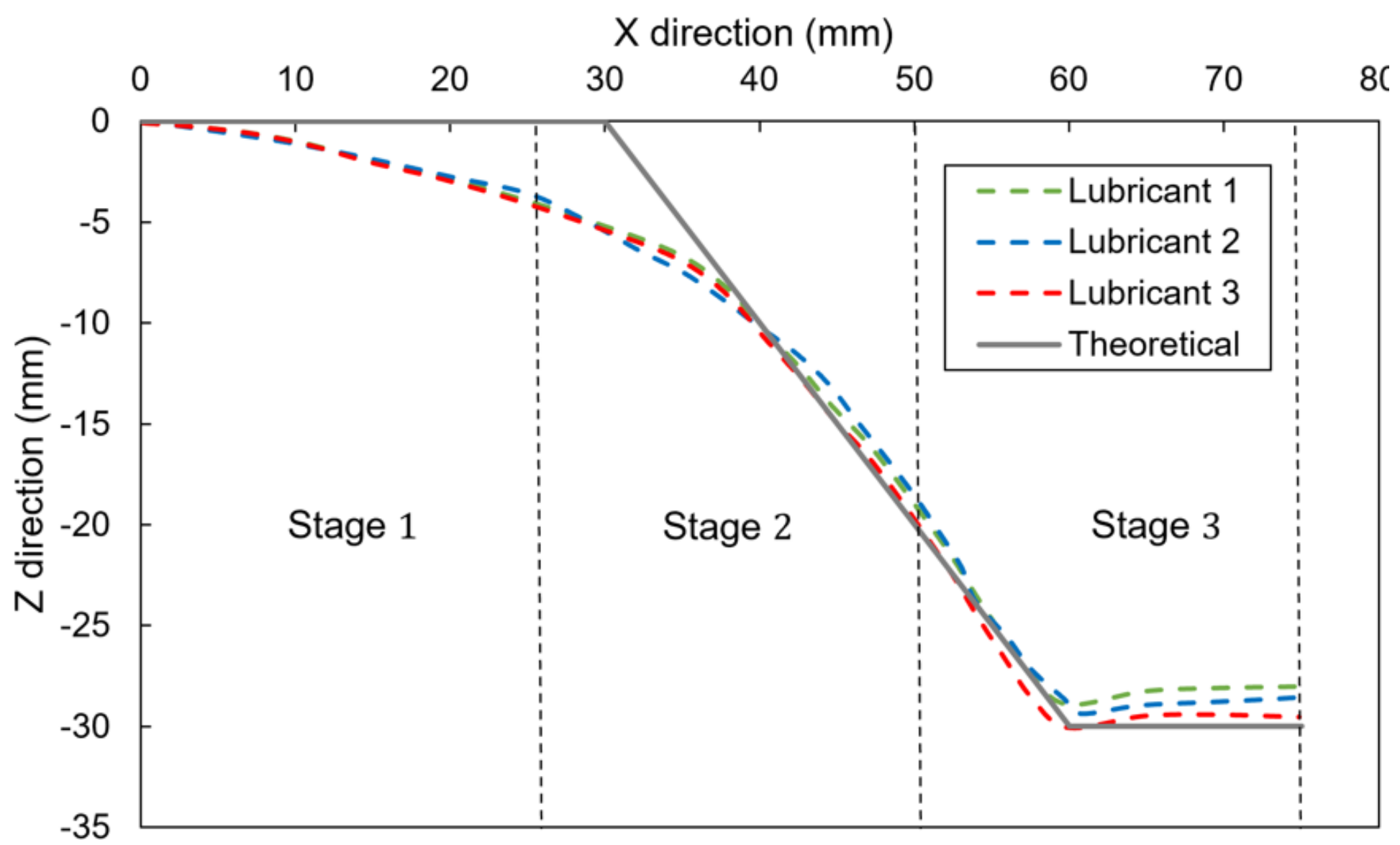

Figure 13

Geometric profile for lubricant 1, 2 and 3 experiments.

Figure 14

Thickness profile for lubricant 1, 2 and 3 lubricant experiments.

Figure 15

SEM images of the deformation surface for lubricant 1: (a) upper region; (b) centre region; (c) lower region.

Figure 16 
SEM images of the deformation surface for lubricant 2: (a) upper region; (b) centre region; (c) lower region.
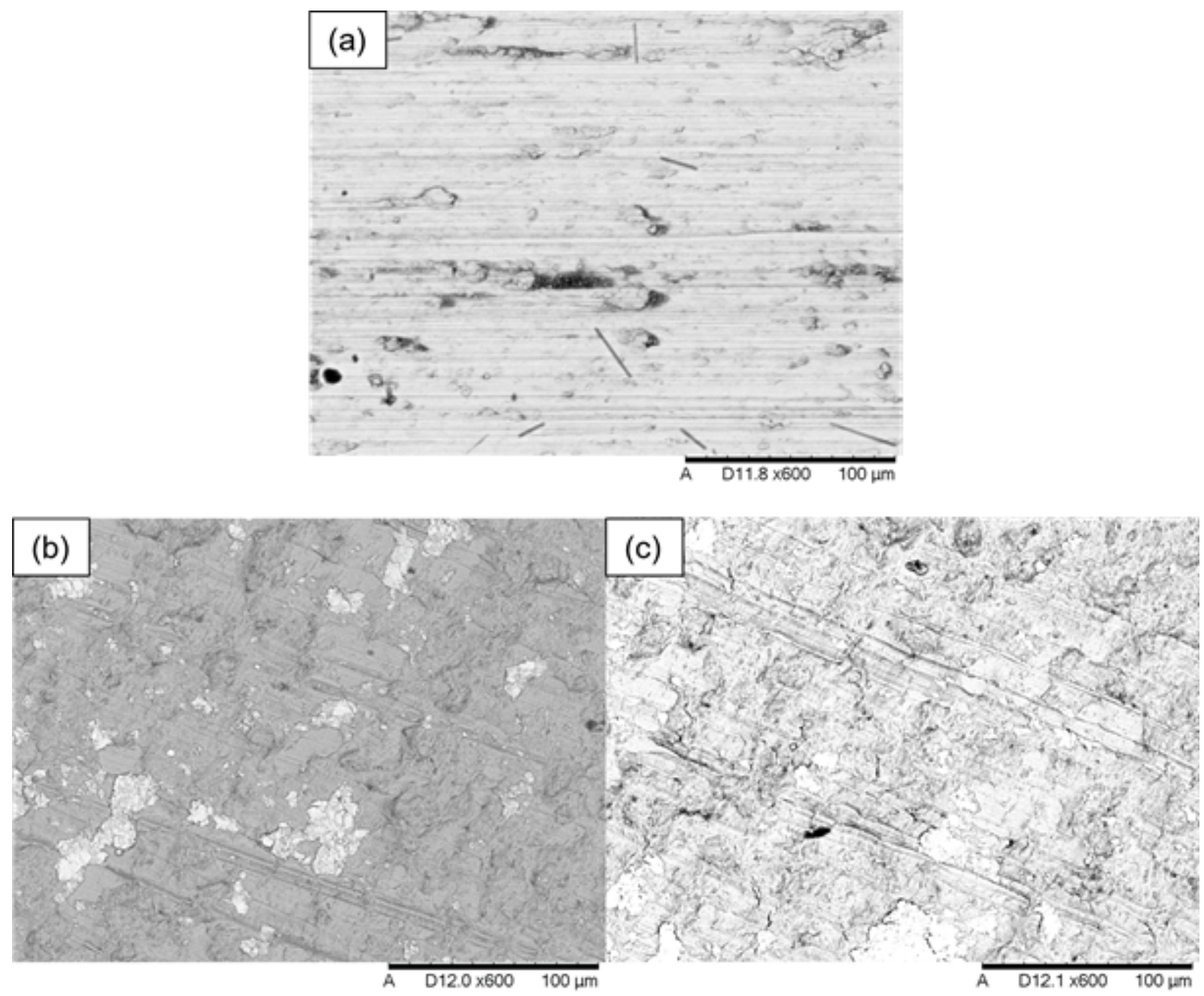

Figure 17

SEM images of deformation surface lubricant 3: (a) upper region; (b) centre region; (c) lower region.

\section{Figure 18}

EDX zone mapping of the lubricant 1 adherence on the surface: (a) upper region; (b) centre region; (c) lower region.

Figure 19 
EDX zone mapping of the lubricant 2 adherence on the surface: (a) upper region; (b) centre region; (c) lower region.

\section{Figure 20}

EDX zone mapping of the lubricant adherence on the surface: (a) upper region; (b) centre region; (c) lower region.

\section{Figure 21}

SEM images of the cross-sectional surfaces of the as-received and deformed workpiece lower region: (a) as-received; (b) lubricant 1; (c) lubricant 2; (d) lubricant 3.

\section{Figure 22}

Micro-hardness profile for deformation surfaces of lubricant 1, 2 and 3 experiments.

\section{Figure 23}

Micro-hardness profile for cross-section surfaces of lubricant 1, 2and 3 experiments. 